\title{
AS RELAÇÕES SUECO-BRASILEIRAS NO INÍCIO DO XIX SÉCULO (1).
}

Em novembro de 1807, alguns meses após a Paz de Tilsit (2), o Moniteur, jornal oficial francês, anunciou a queda iminente da Casa de Bragança. Pouco tempo após, essa afirmativa tornou-se uma amarga realidade para Portugal. As tropas francesas ocuparam o país e a família real portuguêsa foi obrigada a refugiar-se no Brasil, a grande colônia sul-americana de Portugal.

Os acontecimentos transcendentes em Portugal eram a conseqüência do Tratado de Tilsit e da resolução de Napoleão de impor aos Estados europeus o sistema do Bloqueio Continental (3). Sòmente Portugal rebelou-se contra a imposição de Napoleão. A Suécia também não queria se submeter à vontade do ditador francês. Disso resultou que a Suécia também foi atingida por uma catástrofe nacional. Em Tilsit, a Rússia obteve de Napoleão a permissão para conquistar a Finlândia, que as tropas russas ocuparam também em 1808 e que sem tardar, ou seja no ano seguinte, tornou-se um Grão-ducado do Império russo.

(1). - Texto francês traduzido por Josué Callender dos Reis (Nota da Redação).

(2). - Tilsit. Antiga cidade alemā, na Prússia Oriental, incorporada à Rússia com o nome de Sovietsk em 1944. Está situada à margem esquerda do rio Memel, no ponto em que êste conflui com o Tilszele. Tilsit entrou na História devido ao Tratado de Paz de Tilsit, que foi conclúído a 8 de julho de 1807 entre Napoleão Bonaparte e o Tzar Alexandre I (1777-1825). Dêsse Tratado originou-se o reino da Westfália para Jerônimo Bonaparte, com territórios do rei da Prússia; o grão-ducado de Varsóvia para o grão-duque da Saxônia, feito rei; Dantzig foi transformada em cidade livre e o rei da Prússia, Frederico Guilherme III (1789-1840) teve que reconhecer a criação dos reinos da Holanda e de Nápoles para Luís e José Bonaparte, além de outras cláusulas. O Tratado representa, sem dúvida, um dos momentos de máxima potência de Napoleão (Nota do tradutor).

(3). - Conjunto de medidas tomadas por Napoleão Bonaparte para fechar ao comércio da Inglaterra todos os portos do continente, com o fito de arruinar a sua marinha mercante. As principais medidas foram decretadas em Berlim a 21 de novembro de 1806 e causaram grandes prejuízos à Inglaterra, mas contribuiram para ligar tôdas as nações no seu ódio contra Napoleão (Nota do tradutor). 
Portugal e a Suécia tinham isso de comum: dois pequenos países que seguiam uma política anglófila sem grandes considerações pela política de grande potência desenvolvida pela França. Em 1808 a ruptura definitiva de Portugal e da Suécia com a França era muito significativa naquilo que se relacionava com a amizade entre os dois países. O Rei de Suécia, Gustavo IV: Adolfo (4), que detestava Napoleão, devia ter encontrado no interêsse do princípio da legitimidade monárquica tôdas as razões plausíveis para chamar seu agente diplomático de Portugal ocupado pelas tropas francesas; mas outras razões podem igualmente ter motivado sua atitude para com o nôvo regime instituído em Lisboa.

Tradicionalmente a mercadoria de exportação mais importante da Suécia era o ferro. Nos fins do século XVIII e durante o primeiro ano do.XIX, mais ou menos $10 \%$ da exportação total do ferro sueco tinha como destino Portugal e a Espanha. A importação sueca de Portugal compunha-se essencialmente de sal. Mais ou menos em 1800 as mercadorias importadas de Portugal representavam cêrca de 5\% das importações totais da Suécia. Graças à complacência dos inglêses, que queriam comboiar os navios mercantes suecos, durante os primeiros anos do XIX século, a Suécia pôde manter, até certo ponto, suas relações comerciais com Portugal. Em 1806, principalmente, uma frota mercantil carregada de sal deixou Portugal sob escolta de navios de guerra inglêses. Em 1807 as trocas comerciais entre os dois países diminuiram sensivelmente e, no início de 1808, o encarregado de negócios da Suécia em Lisboa, J. A. Kantzow (5), teve que comunicar a seu govêrno que o comércio com Portugal estava em plena estagnação e que os produtos suecos não encontravam mercado de maneira alguma. Nesse momento a Suécia não tinha, pois, interêsse de ordem econômica em manter relações diplomáticas

(4). - Gustavo IV Adolfo, rei da Suécia, filho de Gustavo III (1778-1837). Em 1803 tomou parte na Coligação contra Napoleão. Ao unir-se êste monarca com a Rússia, teve o rei sueco dois poderosos inimigos contra si. Pouco afortunado na sua campanha e mal secundado por parte dos seus súditos, desejosos de paz, viu consternado a sublevação de parte do exército sueco. Em face do perigo da guerra civil alguns oficiais detiveram o monarca. Convocada a Dieta foi êle deposto, sendo sucedido por Carlos XIII (1809-1818) em 1809, que adotou Bernardotte. Desde então andou Gustavo Adolfo errante até a sua morte, usando os nomes de Conde de Gottorf e coronel Gustafsson, tentando em vão a recuperação dos seus direitos, tendo falecido na Suíça (Nota do tradutor).

(5). - J. A. Kantzow, agente diplomático da Suécia em Portugal de 1783 a 1789 , depois de 1797 a 1798 e pela terceira vez de 1804 a 1808 e encarre gado de negócios de 1808 a 1812 (Nota do tradutor). 
com Portugal. Dando ordem a seu representante diplomático de seguir a Côrte em fuga para o Brasil, a Suécia poderia talvez tirar alguma vantagem dêsse país, em compensação da perda do mercado português?

Um apanhado geral sôbre as relações entre a Suécia e o Brasil durante as primeiras décauás do XIX século podem trazer alguma luz, se nos limitarmos aos problemas mais essenciais. Pode-se relatar as coisas mais amplamente como se segue.

Em 1808-1809 a Suécia estava em guerra com a Rússia. A Suécia perdeu a guerra. Houve uma revolução e o país teve um nôvo rei e um nôvo govêrno que deveria capitular ante as potências vitoriosas: a Rússia e a França. Quais eram as repercussões dêsse estado de coisas nos contactos com a Côrte no Rio de Janeiro, protegida pelo govêrno inglês?

Uma outra categoria de fatos que concretizam as relações oficiais entre a Suécia e o Brasil são as negociações tendentes ao estabelecimento dum tratado comercial. As conversações relativas a êsse assunto merecem uma exposição quanto à trocas comerciais de fato entre os dois países nos meados de 1810-1830, época que examinaremos neste trabalho.

Eis primeiramente alguns detalhes sôbre as relações diplomáticas entre a Suécia e o Brasil de 1808 a 1810 (6).

Em fins de janeiro de 1808, devido a uma ordem expressa de seu govêrno, Kantzow deixou Lisboa para dirigir-se a Londres e aí esperar instruções. Pouco tempo depois recebeu êle autorização para se dirigir ao Rio de Janeiro, ao mesmo tempo como encarregado de negócios e como agente geral de comércio. Chegou ao Rio em novembro após uma fatigante travessia, a bordo dum navio inglês.

Pouco tempo depois o diplomata assistiu a acontecimentos políticos espetaculares, que lhe forneceram um abundaante material para os relatórios que enviou para a Suécia. Seus despachos do Rio de Janeiro são muito interessantes, sobretudo porque refletem observações e reflexões dum estrangeiro. Tem-se a impressão que desde o comêço Kantzow teve dificuldades em se adaptar às circunstâncias no Rio de Janeiro, cidade que descreve como

(6). - A descriçāo baseia-se em documentos diplomáticos suecos conservados nos Arquivos Nacionais de Estocolmo. Fizemos um artigo que é um apêndice à nossa tese Latinamerika i svensk politik under 1810-och 1820 talen (A América Latina na política externa da Suécia de 1810 a 1830). Uppsala, 1949. Em 1810-1813 o Brasil tinha uma missāo diplomática na Suécia. O ministro era Lobo da Silveira, que de 1813 a 1814 fol o envíado português, funções que tinha assumido também em 1806-1808. Desde 1817 tìnha o Brasil de nôvo um ministro em Estocolmo. 
"particularmente desagradável, situada num vale cercado de altas montanhas e com falta de canalizações e de cursos dágua para o escoamento das chuvas e das águas servidas".

Ele aliás não tinha obtido alojamento e disse mesmo que após algumas semanas não tinha conseguido encontrar uma "choça" para viver. Parece, entretanto, que se alojou, logo no comêço, na casa do ministro inglês, Lord Strangford (7) que fazia parte do círculo dos seus amigos pessoais.

Kantzow narra com vivacidade detalhes da vida do corpo diplomático na Côrte. Os diplomatas britânicos, os militares e os negociantes, davam a nota na vida do Rio de Janeiro e, segundo as afirmações de Kantzow, eram favorecidos pelo govêrno sob todos os aspectos. O govêrno teria doado, entre outras coisas, ao almirante Sir Sidney Smith (8) uma grande propriedade rural e parelhas de cavalos provenientes das cavalariças reais. Kantzow julgava também que os nobres da Côrte, por todos os meios, tentavam fazer o Regente retornar a Portugal.

Além da Grã-Bretanha, a Suécia era o único país que, após a fuga da família real portuguêsa, tinha transferido os seus diplomatas de Lisboa para o Rio de Janeiro. Nessas circunstâncias, o corpo diplomático devia ser muito reduzido. Kantzow relata que à sua chegada ao Brasil, o corpo diplomático compunha-se do ministro britânico, dum núncio apostólico e dum cônsul dos Estados Unidos. A missão de Kantzow no Brasil indica o desêjo da Suécia em manter relações com o

(7). - Strangford (Lord Visconde de). - Escritor e diplomata inglês, de nome Percy Clinton Sidney Smith. Nasceu na Irlanda em 1780 e morreu em 1855. Foi secretário da legação britânica em Lisboa e Encarregado de Negócios na mesma legação de 1804 a 1807. A sua missão em Lisboa fícou histórica porque teve lugar durante o período em que a França procurou insistentemente extinguir a influencia đa Inglaterra em Portugal e terminar com a aliança luso-britânica. Comboiou a família rea! portuguêsa ao Brasil. Lord Strangford, além de hábil diplomata, distinguiu-se também como escritor de mérito, tendo publicado em inglês uma traduçāo em versos dos Lusíadas, que foi estampada em 1805 (Nota do tradutor).

(8). - Almirante Sir William Sidney Smith. Almirante inglês. Nasceu em Westminster, morreu em Paris (1764-1840). Encarregado de incendiar a esquadra francesa de Toulon em 1793, caiu em poder dos franceses dois anos depois e esteve prêso no Templo, de onde conseguiu escapar. Na Expedição do Egito obrigou Bonaparte a levantar o sítio de São João d'Acre e firmou com Kleber o Tratado de El-Arisch. Em 1807 comandou a esquadra destinada a defender Portugal da invasão francesa. Bloqueou o Tejo e protegeu a famflia real portuguêsa que dêste modo pôde embarcar para o Rio de Janeiro. Vice-almirante em 1818, assistiu a batalha de Waterloo e entrou em Paris com os Allados (Nota do tradutor). 
govêrno legal, e era na realidade uma manifestação anti-francesa. Nesse momento, a Côrte considerava a Suécia como sua aliada na luta contra Napoleão e, por ocasião das suas entrevistas com Kantzow, o Regente pedia informações sôbre a situação no Norte da Europa e sôbre a guerra da Suécia com a Rússia. Tratava-se aqui, naturalmente, de testemunhos de polidês relativamente convencionais. O govêrno do Rio de Janeiro levava ùnicamente em conta os interêsses políticos da Grã-Bretanha. Kantzow julgou muito exatamente a situação quando qualificou Lord Strangford como o verdadeiro dirigente do poder no Rio de Janeiro.

O diplomata sueco tinha recebido do seu govêrno ordens de procurar favorecer as trocas comerciais. O govêrno em Estocolmo tinha anunciado diversas medidas nesse sentido. Com o fito de firmar ainda mais as relações entre os dois países, a Suécia tomou a resolução de enviar um adido comercial ao Rio de Janeiro. O pôsto foi confiado a Lorentz Westin, que anteriormente tinha sido empregado duma casa de comércio em Lisboa. Kantzow, assim como Westin, era interessado em firmas comerciais e nos meios de negócios de Estocolmo e, por essa razão, seu govêrno o exortou a estimular, por intermédio de suas influências pessoais, os comerciantes suecos em estabelecer contactos comerciais com o Brasil.

A grande colônia portuguêsa do Brasil era uma região sôbre a qual se possuia poucos conhecimentos na Suécia. O público sueco teve logo ocasião de aumentar seus dados sôbre êsse assunto. Enquanto que as autoridades suecas tentavam por diversos meios preparar o início das relações comerciais entre os dois países, algumas obras de informação sôbre o Brasil foram publicadas na Suécia. Uma dessas obras tinha por título Informações para aquêles que querem comerciar com o Brasil. Um dos colaboradores dessa publicação era Lorentz Westin, já citado, que nessa brochura esforçava-se para convencer as casas de comércio suecas das vantagens econômicas da importação de produtos coloniais do Brasil. Westin pensava que a Suécia poderia tornar-se um mercado importante para os produtos coloniais do Brasil, produtos que poderiam ser reexportados em seguida para outros países. Compreende-se mais fàcilmente o projeto, se levarmos em conta que certos portos suecos durante a época do Bloqueio Continental, foram centro de trânsito de mercadorias coloniais destinadas ao continente europeu, especulações que eram muitas vêzes muito lucrativas. Somos 
levados a crer que as autoridades, ou o govêrno, inspiravam ou apoiavam a atividade de Westin.

Em 1808, uma outra publicação saiu do prelo com o título de Skizze von Brasilien (Esbôço do Brasil) e o autor era o ministro português na Suécia, Lobo da Silveira (9) que, com essa obra, desejava dar uma orientação geográfica e topográfica do Brasil. No ano seguinte a brochura foi traduzida e publicada em sueco, ao mesmo tempo que um trabalho sôbre o Brasil de autoria do geógrafo alemão E. A. W. Zimmerman.

E' naturalmente difícil julgar quais eram os efeitos da propaganda pró-Brasil. Em todo o caso, o primeiro navio mercante sueco para o Brasil estava prestes a partir em agôsto de 1808 e pode-se apenas considerar como um puro acaso o fato de que o proprietário do navio e o seu carregamento pertenciam à firma Kantzow de Estocolmo. Em 1809, três navios suecos fizeram escala no Rio de Janeiro. Um dêles pertencia à família Westin . Os dois outros navios estavam prestes a levantar âncora mas, por diversas razões, não chegaram ao Rio de Janeiro nesse mesmo ano. As primeiras expedições da história das relações marítimas suecas com o Brasil se fizeram por emprêsas que se pode qualificar de pioneiras, em condições particularmente perigosas. Entretanto, eram emprêsas que tiveram a plena aprovação do govêrno. Um nôvo mercado fêz sua aparição, mas muitas coisas ainda iam acontecer antes que o Brasil se tornasse uma realidade significativa para a política sueca.

Resta mencionar alguma coisa referente aos acontecimentos de 1810. Houve uma séria crise nas relações entre a Suécia e o Brasil. O encarregado de negócios Kantzow abandonou seu pôsto e assim a Suécia não teve mais representação diplomática no Brasil.

Em 1809 o rei Gustavo IV Adolfo, acusado de ser a causa da infeliz política externa seguida pela Suécia, - que teve como resultado a perda da Finlândia - foi deposto. O nôvo rei,

(9). - Lobo da Silveira (D. José Antônio đa Silveira), (17-V-1772 a 27-IV-1848), 7..$^{\circ}$ conde de Oriola (por carta de 5-VIII-1820), datado do Rio de Janeiro, par do Reino (cargo de que não tomou posse) em 30-IV-1826, gentilhomem da câmara de D. João VI, provedor da Casa da fndia, comendador da Ordem de Cristo, enviado extraordinário e ministro plenipotenciário junto à côrte de Estocolmo e mais tarde ao Congresso de Viena (1815), ministro de Portugal em Berlim e embaixador extraordínário em Paris para a coroação de Carlos X. A incompatibilidade política com o sistema constitucional levou-o a naturalizar-se prussiano, perdendo assim a qualidade de súdito português. Na Prússia foilthe reconhecido pelo rei o título de conde (prussiano) para éle e todos os seus descendentes (Nota do tradutor). 
Carlos XIII (10), teve que contentar-se em ser regente duma monarquia constitucional. Como fôsse velho e decrépito e não tivesse filhos, a Suécia se viu forçada a procurar um sucessor para o trono. Como conclusão duma série de acontecimentos, em 1810, um dos antigos marechais de Napoleão foi eleito príncipe real da Suécia, Jean Bernardotte (11) que, em 1818, iria tornar-se rei da Suécia. Parece pois que em seguida a Suécia encontrou-se numa situação muito dependente da França, o que forçou também o govêrno de Estocolmo a aceitar o Bloqueio Continental e a declarar guerra à Inglaterra. Tais acontecimentos tiveram grande repercussão nàs relações oficiais entre a Suécia e o Brasil.

Compreende-se que desde então a situação da Suécia face ao Brasil, tão dependente da Inglaterra, deveria tornar-se complicada. Para o Brasil não era fácil manter oficialmente relações amigáveis com um país que, seguramente constrangido, via-se obrigado a levar uma política que concordava muito pouco com os interêsses britânicos. Compreende-se, pois, muito bem porque o Brasil recusou-se a reconhecer Carlos XIII como rei da Suécia. Kantzow estava pessoalmente convencido de que era o ministro britânico no Rio de Janeiro que se achava por detrás dessa tomada de posição. Segue-se a isso que Kantzow recebeu autorização de seu govêrno para abandonar o seu pôsto. Não se tratava, todavia, duma ordem da parte do govêrno sueco. Deixou-se a decisão inteiramente nas mãos de Kantzow. Este último julgou, entretanto, de bom alvitre deixar o Brasil no início de 1811. Cremos que Kantzow não conseguiu adaptar-se ao Rio de Janeiro. Elle desejava seguramente continuar a sua atividade comercial na Europa - tinha residido mais de 20 anos em Portugal, onde, ao lado de suas funções diplomáticas tinha-se entregue aos negócios - ou prosseguir a sua carreira diplomática. Em 1812 foi, aliás, nomeado ministro nos Estados Unidos, para onde se dirigiu no mesmo ano. O fato era que a família Kantzow, que tinha uma grande casa de comércio em Estocolmo, expor-

410). - Carlos XIII. Irmão de Gustavo III Adolfo, rei da Suécia de 1808 a 1818 , adotou Bernardotte. Em 1814 recebeu a corôa da Noruega, arrancada à Dinamarca (Nota do tradutor).

(11). - Bernardotte (Charles Jean). Marechal de França. Nasceu em Pau, mor reu em Estocolmo. Distinguiu-se nas guerras da Revolução e do Império. Adotado em 1810 pelo rei da Suécia Carlos XIII, olvidou a sua origem para se juntar, em 1813, aos Aliados contra os franceses. Tor nou-se rei da Suécia em $1818 \mathrm{com}$ o nome de Carlos XIV ou Carlos João. A atual casa reinante da Suécia pertence à dinastia por êle fundada (Nota do tradutor). 
tava uma considerável quantidade de ferro para os Estados Unidos, e isso não foi estranho à decisão de Kantzow. E' claro que Kantzow preferiu deixar o Brasil, se bem que o govêrno do Rio de Janeiro procurasse persuadí-lo a ficar. O Regente deu a entender a Kantzow que seu govêrno tinha constantemente de levar em conta a política externa da Grã-Bretanha e pediu a Kantzow que compreendesse as dificuldades do govêrno português no Brasil. Devemos acrescentar que, apesar de tudo, o govêrno do Rio de Janeiro continuou a manter relações diplomáticas com a Suécia.

A partida de Kantzow do Rio de Janeiro e a decisão da Côrte portuguêsa de não reconhecer o nôvo regime da Suécia são fatos que significaram o fim da primeira fase das relações oficiais entre o Brasil, sempre sob o domínio português, e a Suécia. Os conflitos óriundos da grande política da época napoleônica e a impossibilidade para os pequenos Estados de levar avante uma política exterior livre e independente, encontram-se refletidos nos acontecimentos descritos logo a seguir.

Não é inverossímel que as relações oficiais contra a Suécia e o Brasil tivessem tomado um rumo diferente em futuro mais imediato se. Kantzow tivesse permanecido em seu pôsto. O único representante oficial no Rio de Janeiro era agora Lorentz Westin, já citado. No dia 16 de dezembro de 1815, o Regente proclamou a constituição do reino do Brasil em união pessoal com Portugal e já em março do ano seguinte a Suécia reconheceu o govêrno e nomeou o cônsul Westin como seu agente diplomático na Côrte do Rio de Janeiro e a êsse título, em seguida, recebeu êle ordem de seu govêrno de iniciar negociações tendo em vista a obtenção dum tratado de comércio. A êsse propósito deve ser dito que alguns anos antes, isto é, em 1812, a Suécia tinha tentado negociar um tratado comercial com o Brasil. A êsse respeito negociações tinham sido entaboladas em Londres com o ministro português, o conde de Funchal. A Suécia tinha, pois, a intenção de fazer novas tentativas. Esta vez igualmente as negociações não chegaram a resultado algum e para Westin pessoalmente eram elas até então nitidamente humilhantes. A Côrte do Rio de Janeiro declarou não querer negociar com Westin, que era considerado como persona non grata e, em conseqüência, não the reconhecia sua nova dignidade diplomática. Qual era a razão dêsse descrédito? Nessa época, a situação da política interna era bastante instável e dava lugar a uma grande varie- 
dade de opiniões. Westin parece não ter sido completamente estranho às combinações políticas, uma atitude que as autoridades brasileiras deviam naturalmente julgar descabida. Por outras palavras, nas suas atividades comerciais êle tinha se individado e não conseguia satisfazer seus compromissos para com o Banco Nacional.

Parece que no comércio entre a Suécia e o Brasil aplicouse o antigo tratado entre aquela nação e Portugal. O que a Suécia esforçava-se para obter agora eram as mesmas vantagens comerciais usufruídas pela Grã-Bretanha. Por essa ocasião Kantzow tinha calculado que para o comprador brasileiro o ferro inglês, por exemplo, justamente devido às taxas alfandegárias, custava mais barato que o ferro sueco. Da sua parte, o govêrno de Estocolmo seguia uma política amigável em face do Brasil e, para a importação de mercadorias dêste país, como já dissemos, tinha mudado consideràvelmente suas tarifas aduaneiras. Mais ou menos em 1825, a Suécia fêz novas diligências para chegar à conclusão dum tratado. Foi ainda dessa vez Westin quem, nomeado encarregado de negócios, foi designado para negociações, mas êle, após a última vez, ainda não tinha aumentado sua chance para chegar a um feliz conclusão. Não tinha conseguido abster-se de se imiscuir nos assuntos internos do Brasil, e o seu envolvimento nesses assuntos tinha sido tal, que foi atacado na imprensa oficial. Foi acusado de ter conspirado com um diplomata norte-americano contra o govêrno do Rio de Janeiro. Desta vez, também, não houve um tratado comercial entre a Suécia e o Brasil. Não se pode imputar inteiramente a Westin o insucesso. As autoridades brasileiras pareciam satisfeitas com o statu quo das disposições em vigor, quanto ao comércio entre os dois países. E' possível que essa tomada de posição fôsse a conseqüência das atenções do Brasil para com a Inglaterra. Podese dizer, para terminar, que Westin logo deixou seu pôsto de encarregado de negócios, mas permaneceu como cônsul geral.

Entre 1810 e 1820 , as relações oficiais entre a Suécia e o Brasil são essencialmente caracterizadas por negociações sem sucesso no que se refere à obtenção dum tratado comercial e pelo descontentamento das autoridades brasileiras, no que tangia a pessoa do representante da Suécia no Rio de Janeiro. Mas se o que dissemos era tudo o que havia para dizer sôbre a Suécia e o Brasil relativamente a essa época, a matéria de que é objeto êste artigo teria apenas alguma significação 
histórica. Conviria talvez mencionar alguma coisa referente ao comércio entre os dois países tão afastados um do outro.

Entre as mercadorias de exportação da Suécia, ocupava o primeiro pôsto o ferro em barras. Calcula-se que nos meados do século XVIII a Suécia fornecia de 30 a $40 \%$ da produção mundial do ferro. Em 1800 as cifras eram de cêrca de $12 \%$ e em 1850 de $3 \%$. A principal razão dessa regressão era a crescente concorrência do mercado mundial onde, por exemplo, o ferro forjado de hulha inglês tinha encontrado cada vez um mercado maior. No início do século XIX a Suécia começa a procurar novos mercados para mitigar os efeitos da concorrência inglêsa. No fim do século XVIII a Inglaterra tinha sido a maior compradora do ferro sueco, mas algumas décadas mais tarde êsse papel foi tomado pelos Estados Unidos. O sucesso do ferro sueco no mercado norte-americano estimulou o interêsse comercial da Suécia pela América do Sul. De tempos em tempos a imprensa sueca lembrava a importância da América do Norte para o comércio externo da Suécia, sempre sublinhando as possibilidades de negócios lucrativos com a América do Sul. A exportação por via direta do ferro da Suécia para a América do Sul, nas primeiras décadas de 1800, era insignificante. Tratava-se dum número restrito de carregamentos por ano, dos quais a maior parte era destinada ao Brasil. Isso não significa que o ferro sueco também se encaminhasse para a América do Sul por outros canais. Entre 1801-1805 e 1811-1813 a exportação total da Suécia para os Estados Unidos parece ter sido septuplicada. A maioria dessas mercadorias se compunha de ferro. Pode-se bem imaginar que pelo menos uma parte era reexportada rumo à América do Sul. No fim de 1811 Lorentz Westin pôde comunicar a seu govêrno que no Brasil havia solicitação de produtos suecos, principalmente de ferro, mas que êsses pedidos seriam ainda maiores se os norte-americanos não introduzissem grandes quantidades de ferro sueco no pôrto do Rio de Janeiro.

E' notório que por muitas vêzes os inglêses se entregaram a uma concorrência desleal com o ferro sueco, pois chegavam a estampá-lo com marcas próprias. Os britânicos teriam procedido dessa maneira em Trinidad, ilha das fndias Ocidentais, se acreditarmos no que disse o estadista colombiano Francisco Zéa. Não devemos perder de vista que o ferro sueco chegava às vêzes dêsse modo ao continente sul-americano, mesmo que não viesse ao Brasil. Que os suecos não tinham sido capazes de defender melhor os seus interêsses no Brasil é fato 
que podemos atribuir em primeiro lugar à concorrência inglêsa e aos direitos alfandegários vantajosos cobrados na entrada das mercadorias inglêsas. Como já dissemos, Kantzow pelo menos era dêsse parecer e ficou demonstrado pelo que já foi dito, que por várias vêzes a Suécia tinha se esforçado em obter um tratado comercial com o Brasil. Tentou-se claramente obter as mesmas vantagens que aquelas de que gozava a Grã-Bretanha.

Qual era pois a situação da importação sueca dos produtos provenientes do Brasil no início do século XIX? Uma considerável parte dos produtos coloniais, em primeiro lugar o café e o açúcar, que a Suécia importava mais ou menos em 1800, vinha da Inglaterra e da Dinamarca. Os seus países de origem eram sobretudo as colônias britânicas e dinamarquesas das Indias Ocidentais. Nessa época a Suécia importava também, diretamente, diversos produtos chamados coloniais, provenientes da América do Norte. Não podemos averiguar se, e em caso afirmativo, até que grau as mercadorias brasileiras chegavam à Suécia por intermédio de outros países. Durante os primeiros anos do século XIX, a Suécia importava menores quantidades de açúcar de Portugal e é bem provável que se tratasse de produto brasileiro. Durante o período do Bloqueio Continental, não era raro ouvir-se opiniões de que a Suécia deveria procurar reexportar os produtos coloniais importados diretamente. Nessa época era o comércio de trânsito muito rendoso, com mercadorias provenientes da GrãBretanha que davam origem a essas especulações. Está claro que a idéia duma importação lucrativa de produtos do Brasil era atualíssima em 1808, e entre outras coisas, como já relatamos, Lorentz havia sido o porta-voz dêsse projeto.

Foi durante a década de 1820 que a importação de açúcar e de café do Brasil tomou considerável importância. Sòmente no pôrto do Rio de Janeiro carregou-se açúcar e café com destino à Suécia em quantidade, representando respectivamente 15 e $40 \%$ da importação total da Suécia. Em certos anos da década de 1830 , a importação do açúcar do Brasil representava mais da metade da importação global de açúcar. O mesmo acontecia com o café. Durante a década de 1820 o comércio da Suécia com o Brasil tomou proporções tais que se pode falar duma nova orientação do comércio exterior sueco. Pode-se mesmo dizer que em 1830 os produtos brasileiros constituiam aproximadamente $10 \%$ da totalidade das importações suecas. 
Em 1810 a maioria dos navios suecos fazia escala no Rio de Janeiro, mas em seguida os suecos tentaram alcançar também outros portos, principalmente o da Bahia, onde procuraram açúcar. Aconteceu também que os navios mercantes suecos fizeram cabotagem entre o Rio de Janeiro, Buenos Aires e Montevidéu. Os carregamentos eram essencialmente compostos de produtos sul-americanos.

Entre 1820-1825, vinte e cinco navios suecos, em média, por ano, fizeram escala no Rio de Janeiro, de onde a maioria voltava para a Suécia com carregamentos do Brasil.

$\mathrm{Na}$ primeira metade do XIX século, a importação das mercadorias coloniais se fazia, na maioria das vêzes, diretamente dos países produtores. De 1840 a 1850 , o Brasil era um dos quatro primeiros fornecedores de mercadorias importadas pela Suécia. Tarifas baixas favoreciam uma importação direta, mas em 1850 tudo mudou. A importação de mercadorias coloniais pela Suécia se fêz por intermédio dos grandes mercados europeus, isto é, Londres, Amesterdão, Hamburgo, etc., mercados para os quais êsses negócios foram transferidos. A evolução da técnica, entre outras causas, a invenção do telégrafo, mudaram as possibilidades das comunicações por mar, em relação ao comércio transoceânico (12).

Quando Lorentz Westin morreu em 1846, no Brasil, escreveu-se num jornal sueco que êle fôra o verdadeiro criador do comércio sueco-brasileiro e que muitos poucos agentes poderiam ter dado tantas e reais vantagens ao seu país. Se por um lado devemos admitir que Westin muitas vêzes desempenhou suas funções duma maneira a que singularmente faltou flexibilidade, e que pela maneira de se conduzir e de agir dava a impressão duma séria falta de bom senso, não se lhe pode negar a ambição de querer favorecer as relações comerciais entre os dois países, apesar de que na mesma ocasião êle pensasse em seus próprios interêsses. As trocas comerciais entre a Suécia e o Brasil se iniciaram e se organizaram por intermédio da família Westin que possuia muitos navios que velejavam dum país para o outro. A casa Westin em Estocolmo tinha negociado anteriormente com Portugal, mas quando Westin

(12). - I. Hammarström, Svensk transocean handel och sjöfart under 1800-talet (O comércio e a navegação transoceânica sueca no XIX século), in (Historisk Tidskrift", XXV (1962), pp. 377-431. 
deixou êsse país para ir ao Brasil, é êste último que se tornou o objeto principal dos interêsses comerciais dos Westin (13).

Na primeira década de 1800 , o comércio exterior sueco tomou um nôvo aspecto. E' a partir de então que os mercados transatlânticos tornaram-se objeto de interêsse do ponto de vista do comércio para a Suécia. A exportação de ferro para os Estados Unidos e a importação de produtos coloniais do Brasil tornaram-se realidades consideráveis. Mas o govêrno de Estocolmo esforçou-se para dar maior extensão ao comércio com a América e até incluir a América Espanhola. A Suécia não tinha nenhum contacto com as antigas colônias espanholas, mas elas eram o objeto de projetos político-comerciais. Fazia-se planos para exportar ferro e armas para a Colômbia por intermédio da colônia sueca das Indias Ocidentais, São Bartolomeu. A situação nos Estados do Rio da Prata interessava igualmente o govêrno do Estocolmo e em 1817, enviou-se um agente que, in loco, poderia fazer uma idéia daquilo que se passava e das possibilidades de se obter contactos comerciais. O príncipe real, agora Carlos João (Bernadotte) era de opinião que a nova América do Sul revolucionaria inteiramente - mercado mundial. Para difundir na Suéca conhecimentos sôbre a revolução sul-americana permitiu a tradução da conhecida obra de $\mathbf{M}$. de Pradt, Des trois derniers mois de l'Amérique Méridionale et du Brésil. Justamente nessa época a política do comércio exterior se orientava para a América. Foi nesse momento que um nôvo tratado comercial com os Estados Unidos foi assinado e se enviou um agente para junto do estadista argentino Pueryrredón. Pensando nessas coisas, poderíamos concluir que não foi por mero acaso que em 1815 se fêz uma nova tentativa para chegar ao estabelecimento dum tratado comercial com o Brasil. Não pode haver dúvida alguma que a Suécia esperava muito dessa nova América do Sul, independente das potências colonialistas da Europa. No prefácio do editor da tradução sueca da obra do abade de Pradt, está dito entre outras coisas que:

"Pendant plus de deux siècles la terre d'Amérique a souffert sous le poids d'un joug aussi cruel que dégradant

(13). - Durante um curto periodo um irmão de Lorentz Westin foi vice-cônsul na Bahia -e um sobrinho foi durante certo tempo vice-cônsul no Rlo de Janeiro, Lorentz Westin tinha 11 netos e multos membros da sua familia residindo no Brasil. O livro de Axel Paulin, Svenska öden I Sydamerika 1951 (Destinos de suecos na América do Sul) contém informaçóes biográficas interessantes sôbre êsse assunto. 
pour l'humanité, mais l'étoile de liberté attendue a fait. son apparition, de grands et puissants exemples sont donnés et selon toute apparence les derniers liens seront brisés à côté des chaînes que Franklin et Washington ont. déjà rompues".

O conteúdo dessas linhas reflete alguma coisa do romantismo da primeira parte do XIX século e mostra as idéias. que os europeus tinham formado sôbre a América, oriundas do espírito pessimista do após-guerra. Foi dessas idéias que a. política sueco-americana tirou sua inspiração em grande parte.

Quando a família real portuguêsa deixou a Europa em condições dramáticas para dirigir-se à grande colônia sul-americana, a Suécia foi um dos raros países que manifestou sua amizade pelo govêrno legal de Portugal. Os primeiros contactos comerciais com o Brasil tiveram lugar durante uma época de guerra e desolação. Os primeiros navios suecos que velejaram para o Rio de Janeiro realizaram emprêsas iniciadoras. que se podem classificar de aventurosas e cujo resultado era singularmente incerto. Mas elas eram o início dum movimento comercial que continua em nossos dias numa grande escala. Ciências Econômicas. Estocolmo (Suécia). 